\title{
Geometric Constraints and Dynamic Behavior of a Deployable Footbridge
}

\author{
Mariano Molina Iniesta ${ }^{1}$, Fernando del Ama Gonzalo ${ }^{2}$, M. Isabel Castilla Heredia ${ }^{1}$, F. Hernando \\ Mansilla $^{1}$, Dolores Gómez Pulido ${ }^{3}$, J. Carlos Sancho Arellano ${ }^{1}$, Covadonga Lorenzo Cueva ${ }^{1}$, Juan García \\ Millan ${ }^{1}$
}

\author{
${ }^{1}$ San Pablo CEU University \\ Avda. Monteprincipe, Boadilla del Monte, Madrid, Spain \\ molina.eps@ceu.es; isabel.castillaheredia@ceu.es; jc.sanchoarellano@gmail.com, clorenzo@ceu.es; \\ juangmillan@gmail.com; felix.hernando@ceu.es \\ ${ }^{2}$ Keene State College \\ 03435 Keene, New Hamshire, USA \\ fernando.delama@keene.edu \\ ${ }^{3}$ Instituto Ciencias de la Construcción Eduardo Torroja (CSIC) \\ Serrano Galvache St, 4, 28033 Madrid, Spain \\ dpulido@ietcc.csic.es
}

\begin{abstract}
This paper focuses on the design process of a deployable footbridge that meets the requirements of maximum compactness in its folded state, as well as minimum use of auxiliary means during the folding and unfolding process. The fundamental strategy to achieve this is to transform into cables all those elements whose tensile work is guaranteed, taking advantage of the possibility of posttensioning in order to make the whole system stiffer. The suitability of ensuring that these cables will not vary in length when folding the structure, avoiding the need for collection devices, gave rise to a series of geometric constraints that ended up conditioning the design of the prototype. On the other hand, the relationship between post-tensioning and the structure's period of vibration will be discussed, through the development of a dynamic analysis.
\end{abstract}

Keywords: Deployable, Footbridge, Dynamic analysis, Compactness.

\section{Introduction}

Spatial structures with compressed and tensioned elements have become widespread in construction since the 1930s. Flat roofs with long spans and domes made of steel or iron are well known in architecture and engineering applications. All the improvements made to these structures have to do with joints connecting bars or cables. Standardizing prefabricated components increases the time efficiency and safety. It lowers the final costs of labor and reduces risks [1, 2]. Deployable structures made up of prefabricated elements have a stable bearing capacity when the deployment process is completed. The less the energy consumed on deployment, the more efficient the process is [3]. The system presented in this article consists of a foldable, transportable, and deployable structure that allows the construction of temporary walkways, stages, and scaffolds, with a low-cost system and the possibility of being reused. The authors have developed a system that reduces the material needed to fulfill the safety requirements according to the span it covers [4]. The first goal of the presented structure was to become as slender and light as possible to reduce the weight and facilitate transportation and deployment [5,6]. Self-weight significantly influences deployment and bending moments are not relevant in this kind of structure, for all bars and cables are axially loaded [7-8].

There is extensive literature on the structural assessment of this kind of spatial structure, mainly focused on static design. However, slender steel footbridges suffer excessive human-induced vibrations due to their low damping nature and their frequency being located in the range of human-induced excitations [8-10]. The dynamic properties of structures are, among others, the fundamental frequency, the damping ratio, the modal mass, and the mode shape. Building codes address the vibration serviceability design by limiting the static defection or fundamental frequency [11]. The damping ratio is another important property for vibration analysis [12]. Damping ratios measured on full-scale footbridges are the most 
representative reference values for structural design $[13,14]$. The research team has studied the dynamic properties of these structures to improve their safety against human-induced vibration of a long-span steel footbridge. Dynamic forces on footbridges can be applied by pedestrians walking, running, and jumping [15]. The results are expressed as sinusoidal force amplitudes normalized by the subject's weight and are plotted versus frequency. Responses of footbridges are calculated using a simple formula based on the dynamic loading due to one person, the response of a simple span at resonance, and limited duration of excitation. Tuned mass dampers can help reduce the resonant vibrations of the spans [16]. This study aims at predicting the dynamic properties of the structure during the conceptual design phase to enhance its safety.

\section{Geometric constraints}

This section aims to analyze the geometry of two relevant parts of the structure: the basic module of beam and column and the connection between the vertical and horizontal elements. Loads are acting at the nodal points only. This solution reduces the total number of degrees of freedom of the system. The tensioned cables provide the structure with resistance and stiffness and also guide the process of folding and unfolding. Studying the geometry of cables is relevant because the tension cable has to reach its maximum length at the end of the unfolding process. Figure 1 shows the case study comprised of vertical and horizontal deployable elements, the schematics of the unfolding process and, the geometry of the continuous cable subjected to a post-tensioned strain.

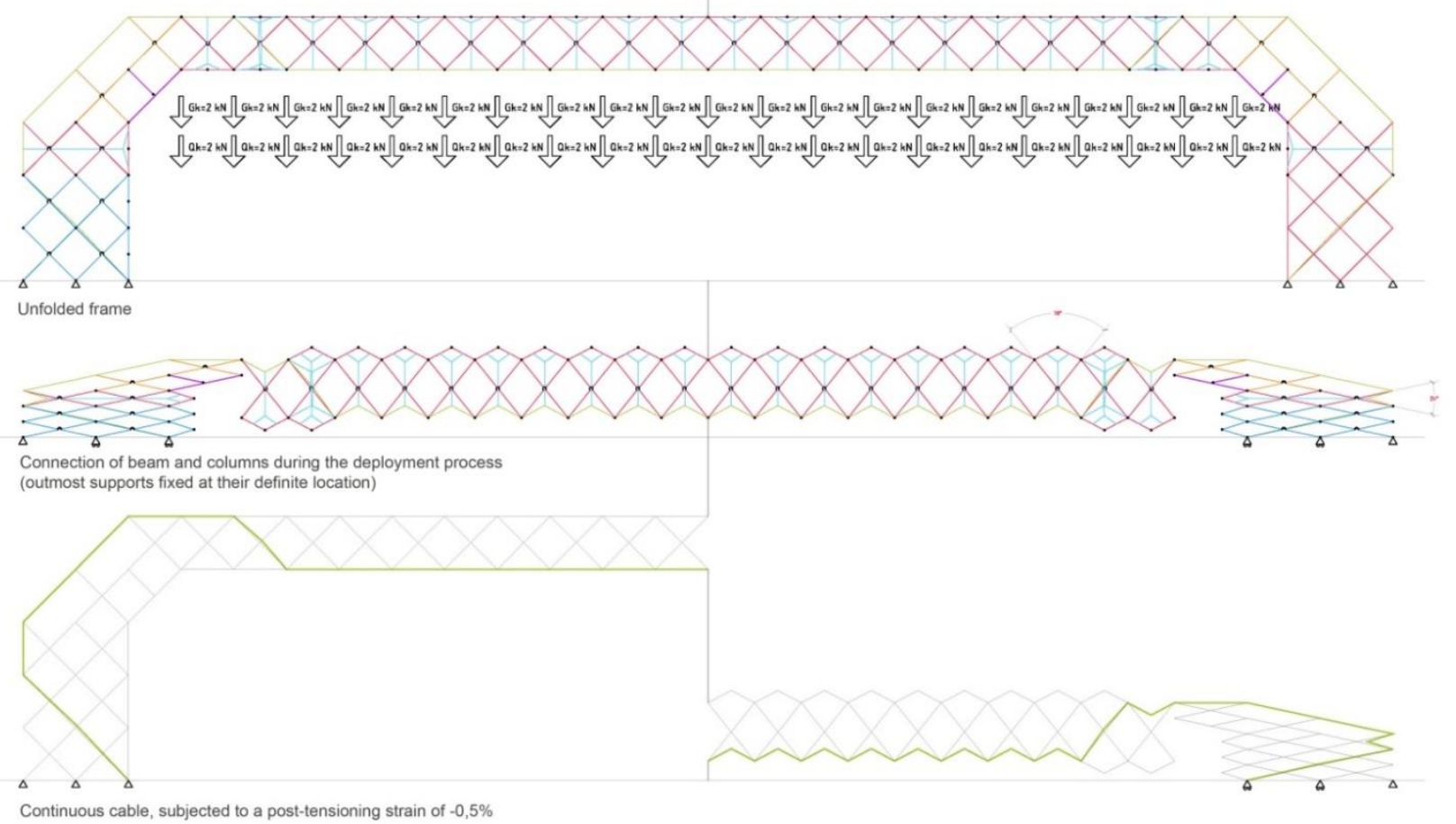

Fig. 1: Schematics of the structure showing the position of loads, the unfolding and, the post-tensioning process.

Due to the scissor connection between diagonals, the bars will be subjected not only to axial tension or compression forces but also to bending moments. Figure 2 shows the bending moments on the structure under vertical loads acting at the nodal points which, exception made of some specific spots, are irrelevant in terms of design. 


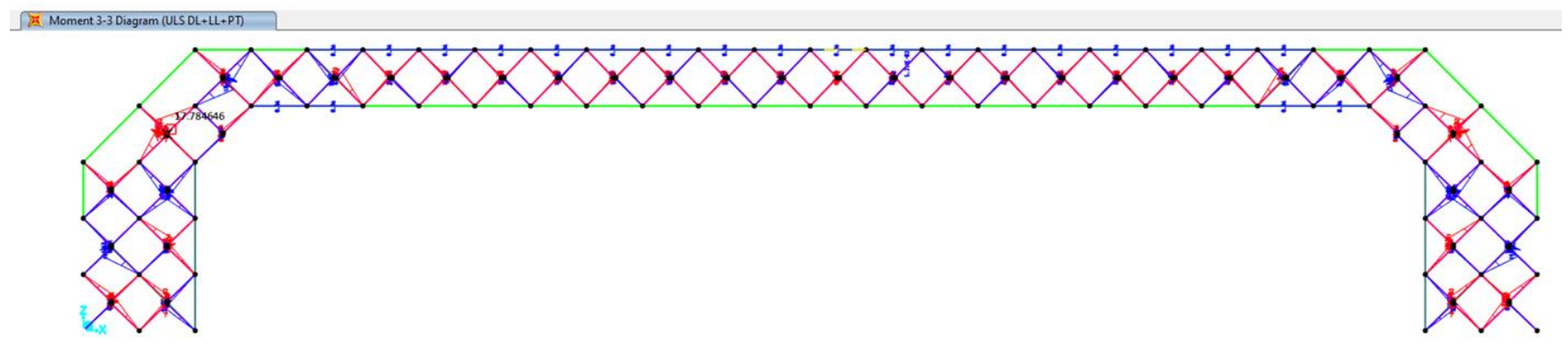

Fig. 2: Bending moments in bars for the ULS check including dead loads, live loads and, post-tensioning.

The next sub-sections show different approaches and justify the final layout of the primary beam elements to manufacture the prototypes. It also explains the adopted geometry for the column element and how the unfolding process must be carried out.

\subsection{Case 1.1. Analysis of the beam's basic module}

Figure 3a illustrates two types of structural members: compressed elements (struts and upper chord) plus a bottom chord carrying tension, which connects points 20,21 , and 11 . One of the challenges when it came to developing a real prototype, was to understand the variation in the chord's length during the folding and unfolding process. The analytical study of this variation showed that the chord experienced phases of increase in its dimension combined with others of decrease. Figure $3 \mathrm{~b}$ shows the changes in the length of the chord throughout the unfolding process. Equation (1) shows the length of the tension cable for a $2 \times 2$ meter basic module. This circumstance forced complex operations of post-tensioning to make the cable perform its function.

$$
L=2 \sqrt[2]{2} \sin \frac{\propto}{2}+\sqrt[2]{\left(\sqrt[2]{2} \sin \frac{\propto}{2}\right)^{2}+\sqrt[2]{\left(1^{2}-\left(\sqrt[2]{2} \sin \frac{\propto}{2}\right)^{2}\right)^{2}+\left(2 \sqrt[2]{2} \cos \frac{\propto}{2}\right)^{2}}}
$$
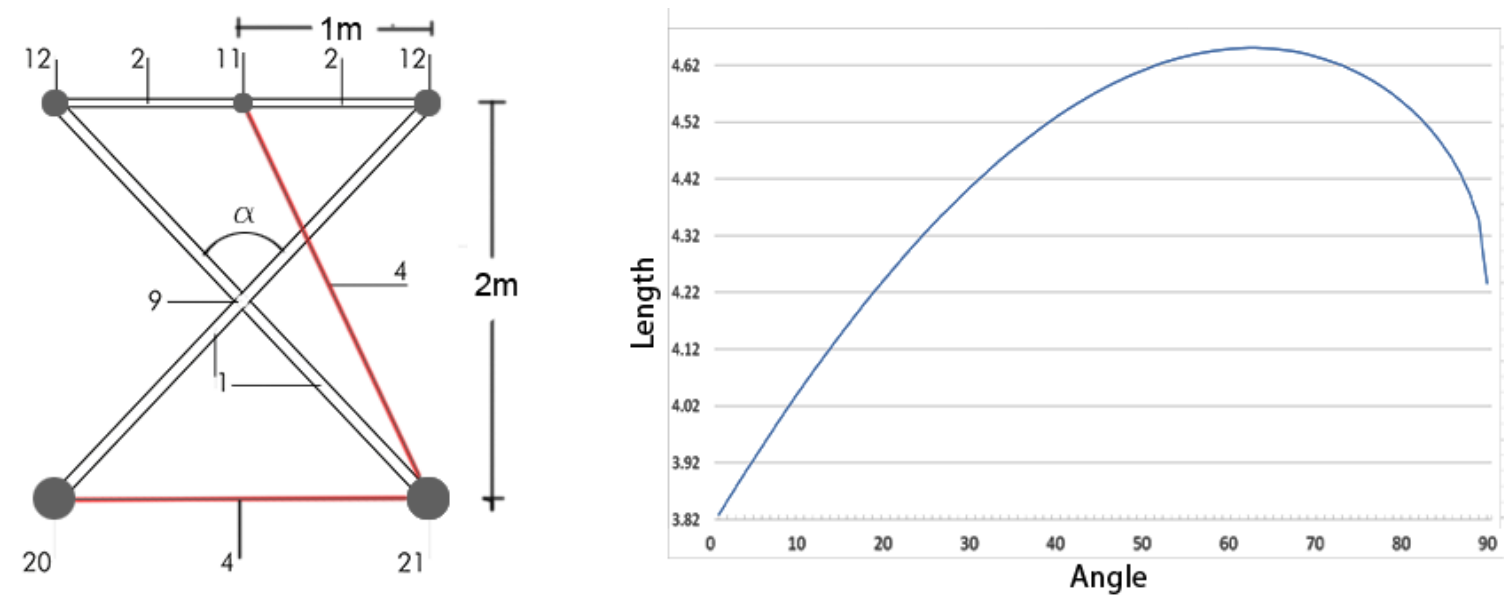

Fig. 3: a) Basic module. It consists of two hollow diagonal bars (1) with a scissor connection at their middle point (9) and compression bars (2). The tension cable (4) connects nodes (11), (20) and (21); b) length of the tension cable during the unfolding process.

The second version of the prototype solves the problem found in the first version. Figure 4 shows that, by splitting the tension element into two, the maximum length of the chord takes place at the end of the unfolding process. Equation (2) shows the analytical expression of the chord's length. 
$L=2 \sqrt[2]{2} \sin \frac{\propto}{2}+\sqrt[2]{2 \sqrt[2]{2} \cos \frac{\propto}{2}+\sqrt[2]{1-\left(\sqrt[2]{2} \sin \frac{\propto}{2}\right)^{2}}-\sqrt[2]{x^{2}-\left(x \sqrt[2]{2} \sin \frac{\propto}{2}\right)^{2}}-\sqrt[2]{\left(y^{2}-\left(x \sqrt[2]{2} \sin \frac{\propto}{2}\right)^{2}\right)^{2}-\left(\sqrt[2]{2} \sin \frac{\propto}{2}\right)^{2}}}$

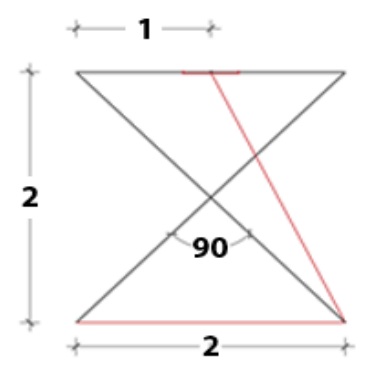

a)

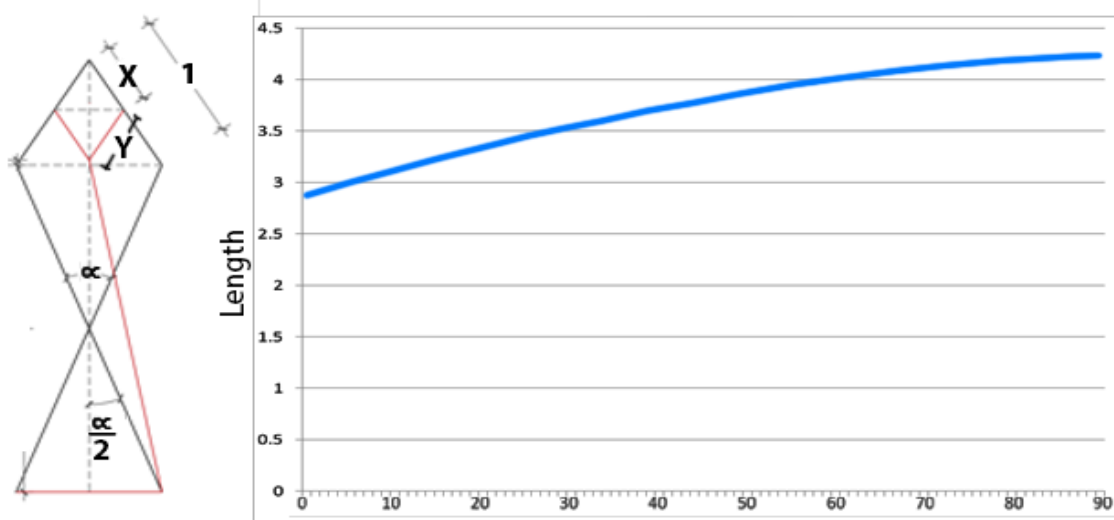

b)

Fig. 4: Proposal for splitting the tension member a) and the resulting variation in length b).

The third option changes the geometry of the module. A vertical cable connecting the middle points of the tensioned and compressed chords replaces the diagonal element connecting point 21 to point 11 . Equation 3 has been used to calculate the length of the chord as a function of $\mathrm{x}$ and $\mathrm{y}$, and Figure 5 illustrates the new geometry and shows that the initial and final lengths of the cable are the same.

$$
L_{\text {cable }}=2 \sqrt[2]{2} \cos \frac{\propto}{2}-y \sqrt[2]{1-\left(\sqrt[2]{2} \sin \left(\frac{\propto}{2}\right)\right)^{2}}-\sqrt[2]{\left(x^{2}+y^{2}\left(1-\sqrt[2]{2} \sin \left(\frac{\propto}{2}\right)^{2}\right)\right)}
$$

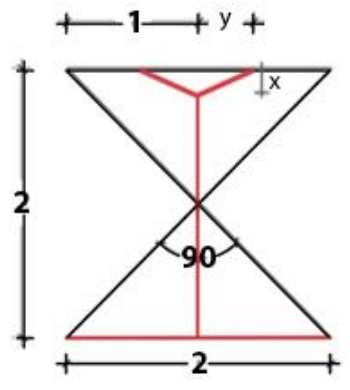

a)
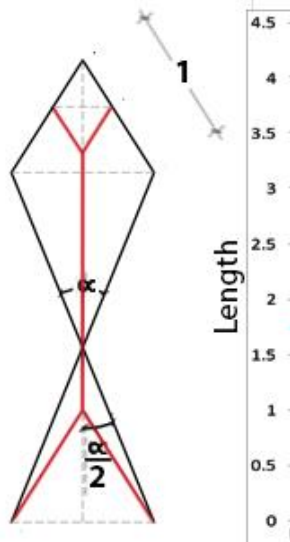

(6)

Fig. 5: Proposal of a cable connecting the middle points of chords a) and the resulting variation in length b).

Figure 6 shows a 3D model of the final version of the prototype. 

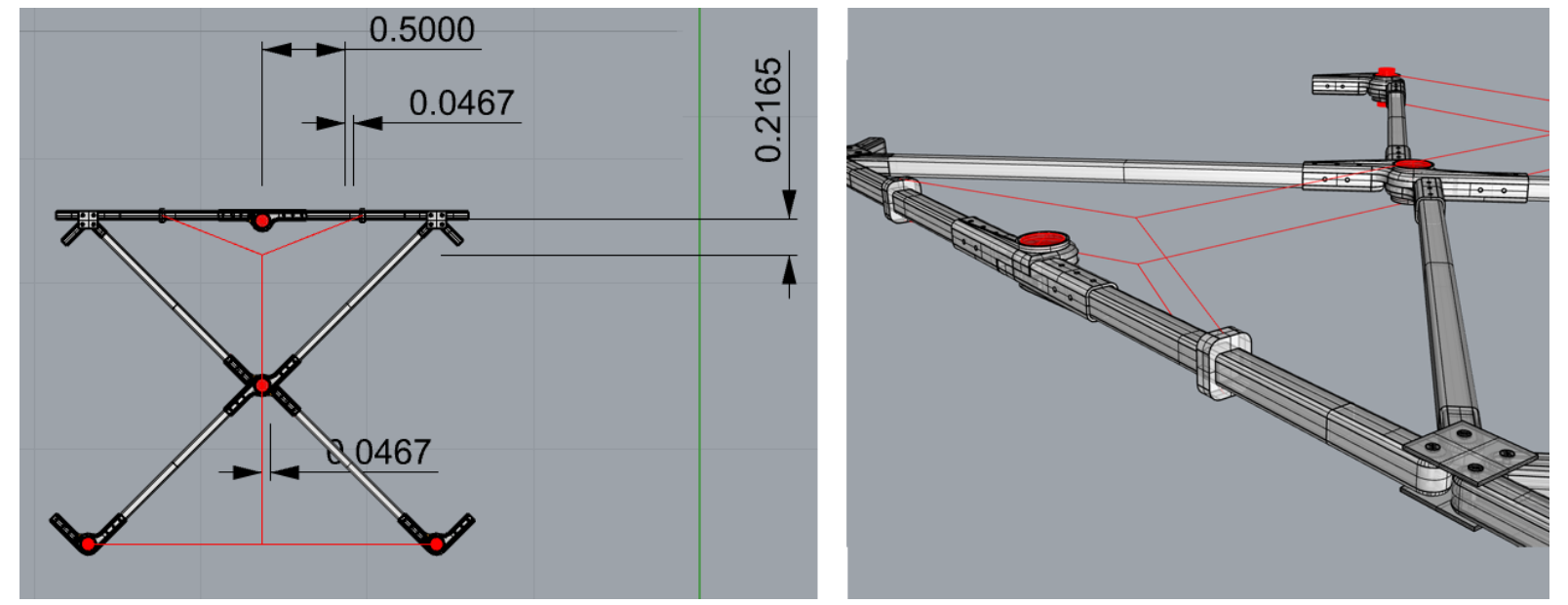

Fig. 6: 3D model of the prototype with the final dimensions.

\subsection{Case 1.2. Analysis of the column's basic module}

The same goal inspires the design of the column's basic module. Figure 7 illustrates the initial and final lengths of the cable, whereas equations 4 and 5 show the analytical expressions of the variable length of the chord.

$$
L=4 \sqrt[2]{2} \cos \frac{\propto}{2}-\sqrt[2]{2 \cos \propto+(1-y) \sqrt{\left(1-\left(\sqrt[2]{2} \sin \left(\frac{\propto}{2}\right)\right)^{2}\right)}}-\sqrt[2]{\left(x^{2}+y^{2}\left(1-\sqrt[2]{2} \sin \left(\frac{\propto}{2}\right)^{2}\right)\right)}
$$
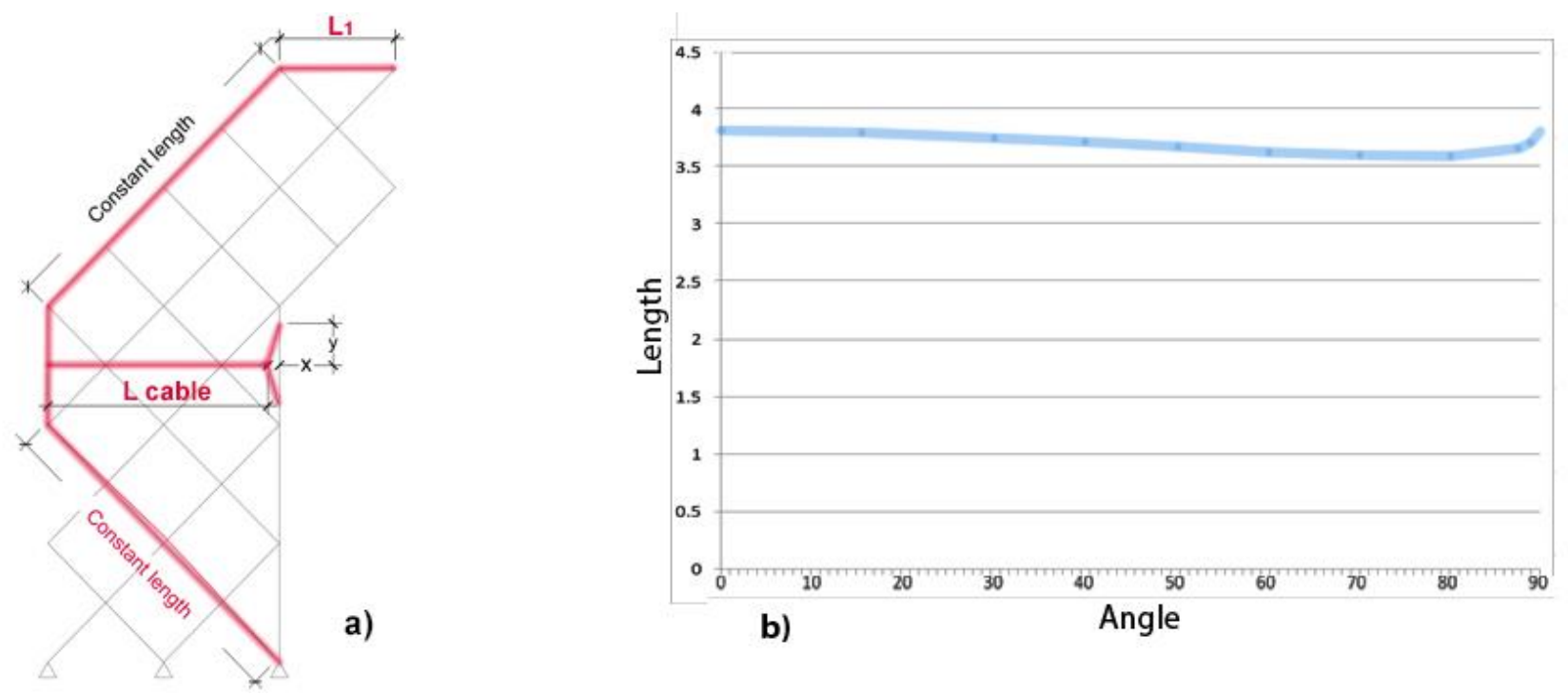

Fig. 7: Proposed geometry of the cable in the column a) and the resulting variation in length b).

\subsection{Case 2. Analysis of the connection between vertical and horizontal elements}

The goals that have been pursued when designing the connection between the columns and beam have been, on the one hand, guaranteeing the continuity of the tensioned element, and on the other hand, being able to unfold and lift the beam at the same time. To achieve this, both columns have to be placed in such a way that the furthest supports will remain at the same position during all the deployment process. The deployment process will begin for columns and beam as 
independent entities, until the point when the overall length of these three elements in a semi-folded state will match the final length of the frame. It also happens that, in that precise moment, the beam is not lifted from the ground yet, which makes the use of auxiliary means unnecessary. The geometry of the constituting elements of the frame at that particular moment is illustrated in figure 8 :

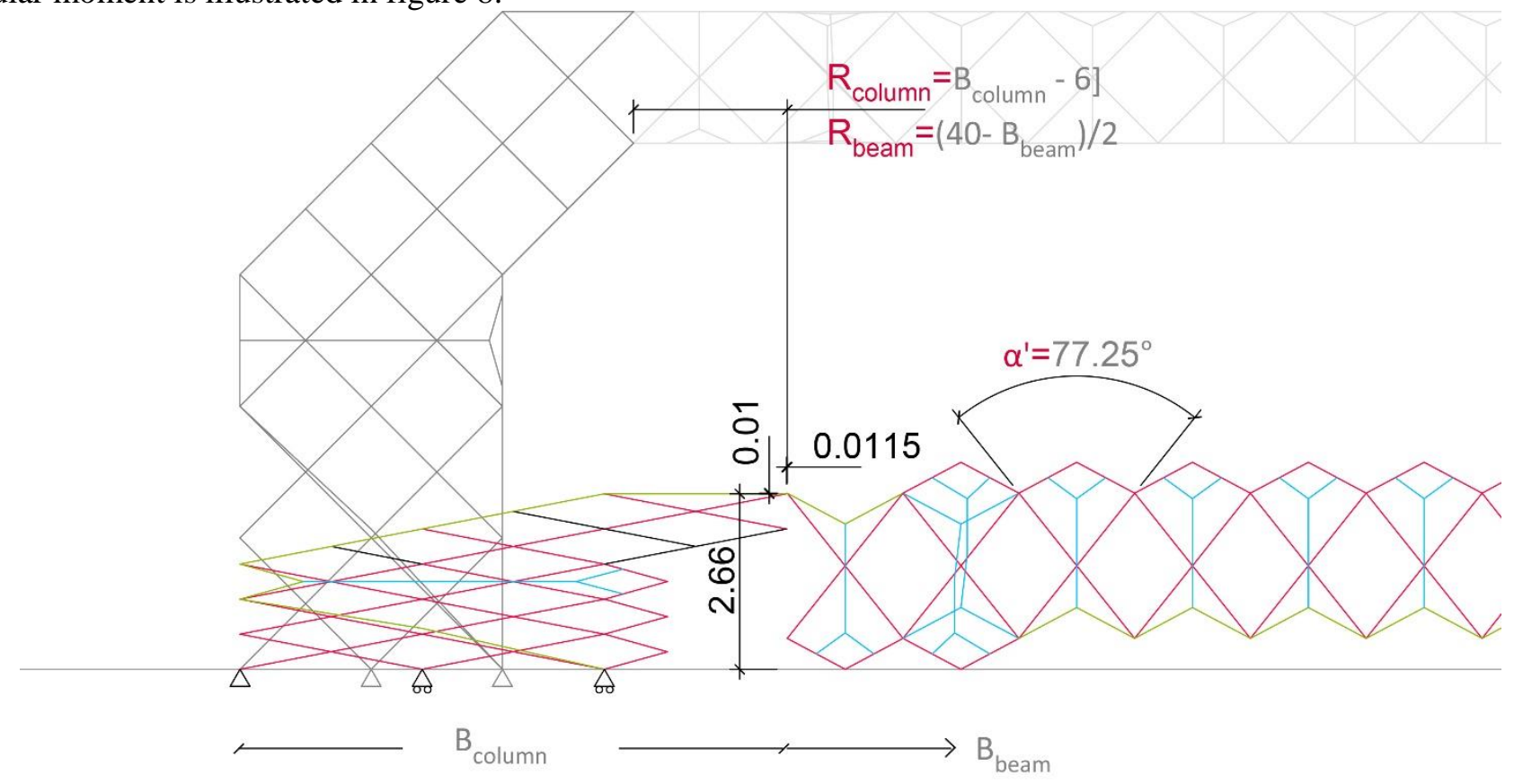

Fig. 8: Level of deployment when the beam and the columns get connected to each other.

As of that moment, the three elements act as a single entity, since the columns will become more slender and the beam wider, keeping the total length of the system constant. Once the system is fully deployed, the only remaining action is to connect the bottom chord of the beam with the top of the columns.

\section{Dynamic analysis}

The post-tensioning of the cable proved to be very efficient in terms of stiffness, being able to counteract significant initial deflections and even cause upward displacements in the midpoint of the span. Figure 9 shows how a downward deflection of almost $30 \mathrm{~cm}$ becomes an upward displacement of $15 \mathrm{~cm}$ when a strain of $-0.5 \%$ is added to the system. That means that the proper performance of the frame is guaranteed when it comes to static loads.

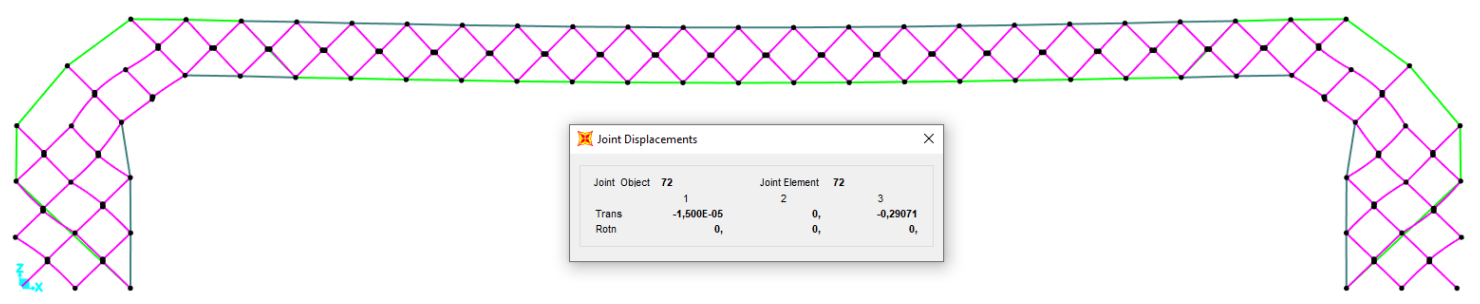




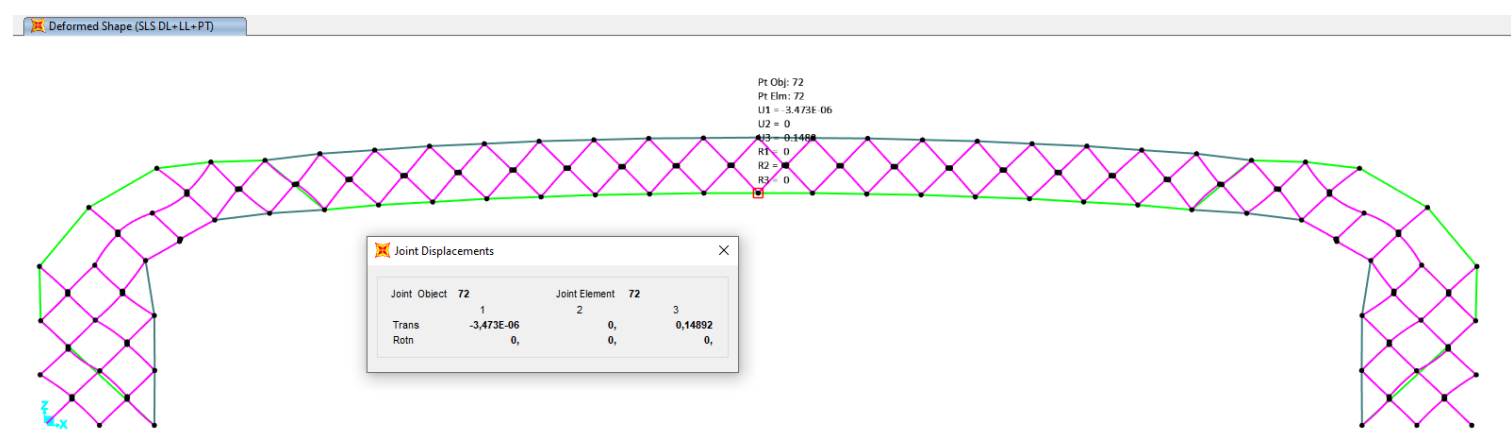

Fig. 9: Effect of post-tensioning on the deflection of the beam.

However, if this structure is to be used as a pedestrian footbridge, it has to be equally effective in terms of vibrations. The footbridge is simply supported and $55.2 \mathrm{~m}$ in length. Because it is slender and light, it suffers from excessive humaninduced vibrations. The footbridge finite element model -built in SAP2000- is analyzed, firstly, taking into account the vibrations in the plane of the main frame. The model in SAP2000 and the results of the first analysis are shown in Figure 9.

One of the potential weaknesses of the proposed structure is its behavior against vibrations, especially if it will be used as a footbridge. In this regard, the Spanish Technical Code requires that the proper vibration frequency of the structures be higher than $3.4 \mathrm{~Hz}$ (for spaces devoted to public use with no fixed seats) up to $8 \mathrm{~Hz}$ (for high-frequency dynamic loads, such as those that happen in gyms or similar spaces). The first analysis considers only the vibrations that occur in the plane of the main frame. SAP2000 is used to perform the modal analysis of the model. The initial conclusions that are drawn are that the structure is far from reaching the recommended frequency values, and moreover, that the post-tensioning does not act as a corrective effect on this problem. The post-tensioning corrects the deformation, but does not imply an increase in effective stiffness, and therefore does not modify at all the proper vibration frequency of the structure. If we consider only the mass of the self-weight, the frequency of the structure is $2.15 \mathrm{~Hz}$, and if we add the permanent load as a source of mass, this frequency is reduced to $1.22 \mathrm{~Hz}$. In any of these cases modifying post-tensioning values has no effects on frequency.

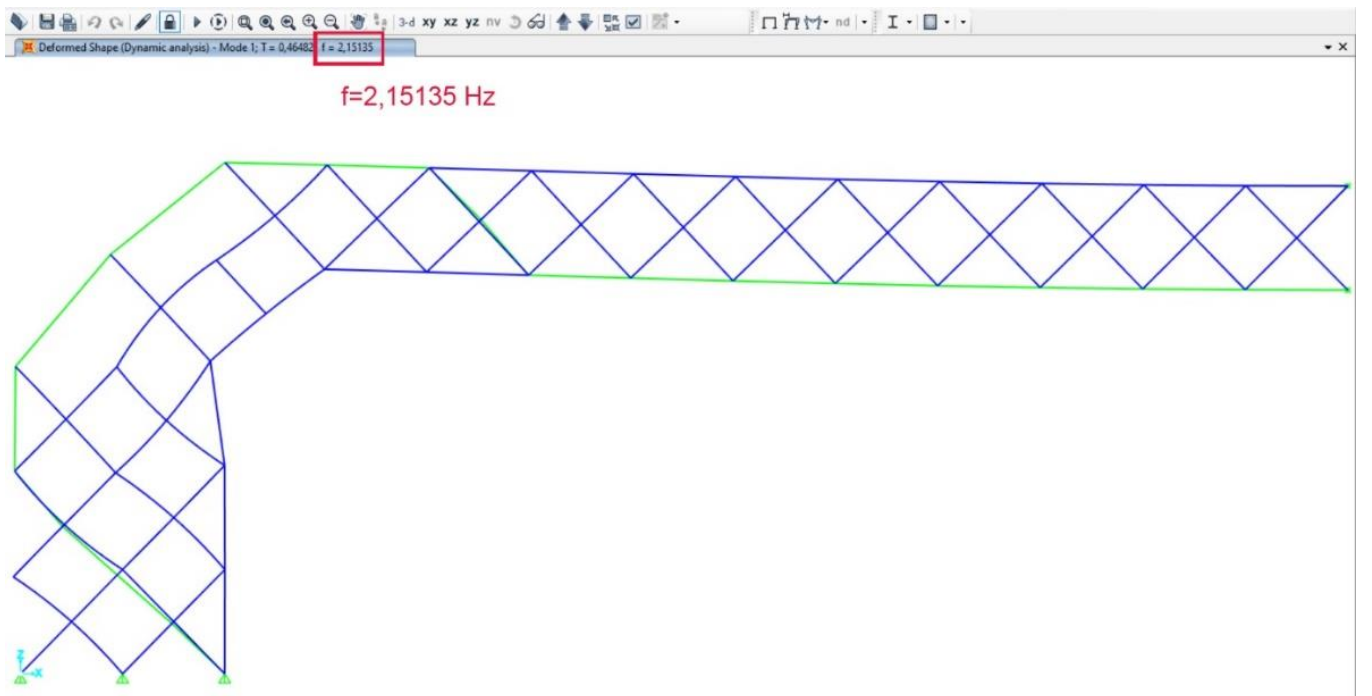

Fig. 10: Vibration frequency of the footbridge considering only mass due to the frame's self-weight.

To validate the results, a 40-meter span beam with pinned/roller support types is analyzed and only mass due to selfweight of structural members is considered. The vibration frequency of this beam depends on the mass and its stiffness. The deflection at the midpoint due to self-weight is $6.84 \mathrm{~cm}$. The equivalent moment of inertia is, therefore, $1.158 \cdot 10^{-3} \mathrm{~m}^{4}$. Equation 6 shows the analytical expression of the vibration frequency. 


$$
f=1,5743 \cdot \sqrt{\frac{E \cdot I \cdot g}{q \cdot L^{4}}}=2,148 \mathrm{~Hz}
$$

Where $\mathrm{E}$ is the Young modulus, $\mathrm{I}$ is the moment of inertia, $\mathrm{g}$ is the acceleration of gravity, $\mathrm{q}$ is the self-weight of the structure, and L is the span. The result of equation 6 matches the value form the SAP2000 simulation shown in figure 11 .

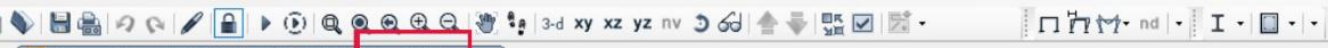

Deformed Shape (MODAL) - Mode $1 ; \mathrm{T}=0,479 ; ; \mathrm{f}=2,08556$

\section{$\mathrm{f}=2,08556 \mathrm{~Hz}$}

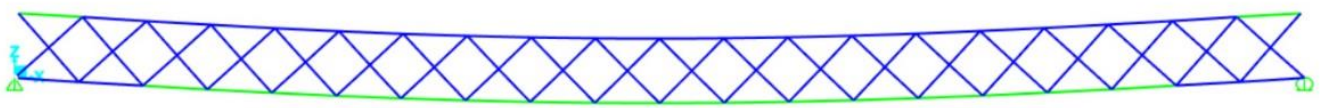

Fig. 11: Vibration frequency of the footbridge considering pinned support types.

The slight difference between the cases analyzed in figure 10 and figure $11 \mathrm{can}$ be explained because the former has a slight constraint to rotation at both ends. The next case shows the same example as in figure 11 with fixed ends so that the rotation is constrained. Figure 12 illustrates that the cable at the bottom chord gets loose at both ends due to the change in the curvature of the beam. This causes a loss of stiffness in the system. The deflection at the midpoint of the span due to its weight had to be $1 / 5$ of that obtained in the pinned/roller beam. However, the actual deflection is $1.93 \mathrm{~cm}$, which is $28 \%$ of the deflection of the pinned/roller beam.

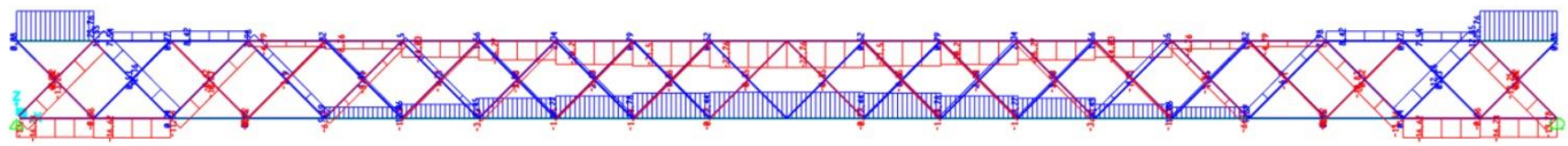

Fig. 12: Tension and compression of chords and struts considering fixed supports.

Taking into account the new deflection, the new moment of inertia is $8,208 \cdot 10^{-4} \mathrm{~m}^{4}$, and the new frequency is shown in equation 7

$$
f=3,5842 \cdot \sqrt{\frac{E \cdot I \cdot g}{q \cdot L^{4}}}=4,118 \mathrm{~Hz}
$$

It is this loss of stiffness due to the loosening of the bottom cable, which causes the discrepancy with frequency obtained in the SAP2000 model, being $4,844 \mathrm{~Hz}$ instead of 4,118. In any case, the different attempts at computing the frequency of the frame prove that post-tensioning cannot be considered as an improving strategy, having no significance at all on its dynamic behavior. Tuned mass dampers (TMDs) with well-designed parameters can be used to control the in-service human-induced vibrations of slender footbridges. The effect of multiple TMDs will be the subject of future research.

What the analogy with the pinned and the fixed beam allows us to obtain is the degree of fixity of the real beam in the frame. Accepting the results provided by the different SAP2000 models, it would be:

$$
D=\frac{2,15-2,08}{4,844-2,08}=0,025=2,5 \%
$$

That is, almost identical to a 40-meter pinned beam. 


\section{Conclusion}

The design presented and described in this paper has proved to be very effective in many regards: it has maximum compactness; guarantees the continuity of the tensioned element; allows for deployment with minimum auxiliary means, and keeping the total length of the cable constant, makes collection devices unnecessary. On the other hand, the posttensioning operation dramatically improves the deflections for static loads. Being considered a sort of stiffening device, it was attempted to see if post-tensioning had the same effect on the frame's dynamic behavior. Unfortunately, it does not, having to be considered merely as another action on the frame that counteracts the effect of the gravitational loads. Therefore, to increase the frequency of the frame so that it will be suitable to be used as a pedestrian footbridge, tuned mass dampers will need to be added to it. On the positive side, the comparison with the pinned and fixed isolated beam allowed us to define the degree of fixity of the beam in the real frame.

\section{Acknowledgements}

The work presented in this paper was supported by the project DEployable Structures of MAximum Compactness (DESMAC) granted by San Pablo CEU University. The article has been partially funded by KSC Faculty Development Grant (Keene State College, New Hamshire, USA).

\section{References}

[1] M. Noguchi, C.R. Hernàndez-Velasco, "A mass custom design approach to upgrading conventional housing development in Mexico," Habitat International, vol. 29, pp. 325-336, 2005.

[2] S. A. Saafan, "Theoretical Analysis of Suspension Bridges," Journal of the Structural Division, vol. 92, no. ST4, 1966.

[3] L. Qiang, R. Skelton, and Y. Jie, "Energy optimization of deployable tensegrity structure," in Control Conference (CCC), 30th Chinese, pp. 2146-2151: IEEE. 2011.

[4] F. del Ama, M. Molina, M.I. Castilla, D. Gómez, C. Lorenzo, J. García and J.C. Sancho. "Numerical Simulation and Experimental Study of a Deployable Footbridge" IOP Conf. Ser.: Mater. Sci. Eng., vol. 603, 2019.

[5] J. Aversenga, J. F. Dubéa, "Design, analysis and self-stress setting of a lightweight deployable tensegrity modular structure," Procedia Engineering, vol. 40, pp. 14-19, 2012.

[6] J. Quirant, F. Cevaer, S. Morterolle, B. Maurin, J. F. Dube, "Conceptual Design and Analysis of a Deployable Structure with Flexible Joints," Journal of Aerospace Engineering, pp. 277-284, 2011.

[7] H. Guo, W. You, "Design optimization of planar linkage mechanism with joint clearance for improving the robustness of kinematic accuracy," Journal of Mechanical Engineering, vol. 48, no. 3, pp. 75-81. 2012.

[8] M. Kasperski, "Vibration serviceability for pedestrian bridges," Proc Inst Civ Eng Struct Build, vol. 159, pp. 273-82, 2006.

[9] S. Živanović, J. Russell, M. Pavlović, X. Wei, J. T. Mottram, "Effects of pedestrian excitation on two short-span FRP footbridges in Delft," Pakzad S, editor. Dynamics of civil structures, vol. 2. Cham: Springer International Publishing; 2019 , p. 143-50.

[10] Bachmann H, Ammann WJ, Deischl F, Eisenmann J, Floegl I, Hirsch GH, Klein GK, Lande GJ, Mahrenholtz O, Natke HG, Nussbaumer H, Pretlove AJ, Rainer JH, Saemann EU and Steinbeisser L. Vibration problems in structures: practical guidelines. Birkhauser; 2012.

[11] HA. Design of FRP bridges and highway structures, Part 17, BD 90/05. Highways Agency, pp. 143-50, 2005.

[12] G. P. Tilly, D. W. Cullington, R. Eyre, "Dynamic behaviour of footbridges," IABSE Surveys S-26/84. IABSE Periodica, pp.13-24,1984.

[13] E. Lai, C. Gentile, M. G. Mulas, "Experimental and numerical serviceability assessment of a steel suspension footbridge," J Constr Steel Res, pp. 132:16-28, 2017.

[14] P. Hawryszków, R. Pimentel, and F. Silva, "Vibration effects of loads due to groups crossing a lively footbridge," Procedia Eng. 199, pp. 2808-2813, 2017.

[15] S. Ivorra, D. Foti, F. Paparella, and F. Javier Baeza, "Dynamic load tests on the North-South axis cable-stayed bridge with a non-symmetric central pylon, Procedia Eng., vol. 199, pp. 2967-2972, 2017.

[16] Q. Peng, S. Wang, C. Zhi, B. Li, "A New Flexible Multibody Dynamics Analysis Methodology of Deployable Structures with Scissor-Like Elements," Chinese Journal of Mechanical Engineering, vol. 32, no. 1, 2019. 